\title{
CONDITIONS AND CHARACTERISTICS OF COAL WATER SLURRY CONTAINING PETROCHEMICALS IGNITION BY HOT PARTICLE
}

\author{
Nina K. Gal'chenko ${ }^{1}$, Valeriy V. Medvedev ${ }^{2}$, Aleksandr G. Nigay,", , and Dmitriy S. Sivkov² \\ ${ }^{1}$ Institute of Strength Physics and Materials Science SB RAS, 634055 Tomsk, Russia \\ ${ }^{2}$ National Research Tomsk Polytechnic University, 634050 Tomsk, Russia
}

\begin{abstract}
Characteristics of CWS containing petrochemicals ignition by single hot particle in disk shape established experimentally. The main components of fuel composition are coal $45 \%$, water $45 \%$, used engine oil $10 \%$. The main parameters of local heat sources are: material - steel, diameter $10-12 \mathrm{~mm}$, high $4-8 \mathrm{~mm}$. As a result of experimental study is established limit (minimum) conditions for ignition of CWS containing petrochemicals by hot particle and the impact of local heat source parameters on the main process characteristic - ignition delay time.
\end{abstract}

\section{Introduction}

The urgency of investigating of ignition characteristics of new fuels based on coal suspensions associated with the major scientific problem, which includes two tasks: recycling of solid and liquid combustible waste of coal and oil refineries, low-grade solid fuel, used oils; power generation by burning such fuel compositions.

Last years fuels based on the coal-water slurry used for power generation in countries with dynamically developing fuel and energy complex (China, India, USA, Germany). Coal-water slurry (CWS) has advantages in comparison with typical solid and liquid fuels for thermal power plants: high environmental characteristics, fire safety in preparation for burning, economical operation of power plants.

The technological process of CWS burning similar to the processes that take place in the furnaces of coal-fired boilers. However, there are some differences. The main features of the combustion process for CWS are: low-temperature surface activation reaction at the fuel ignition stage, the growth of the specific reaction surface in the main combustion zone, due to the intensification of the interaction reaction of carbon with water vapor.

Last years various characteristics of CWS research numerically [1-3] and experimentally [4-6]: rheological characteristics, methods of preparation, transport and storage, combustion parameters. Developments of furnaces construction for efficient combustion of CWS, conducted by the authors [7, 8], have a great importance for the practice.

\footnotetext{
${ }^{*}$ Corresponding author: nigayalexandr@mail.ru
} 
Highly promising direction in the development of CWS subjects is to create new composite liquid fuels on their basis (CWS containing petrochemicals) that consists of three main components: coal, water and combustible petrochemicals (motor, turbine, transformer, transmission oils) [9-12]. Results of combustion processes research of such fuels let us develop the theoretical bases of recycling technology for a large group of industrial facilities to energy production.

The purpose of present work is the experimental study of limit (minimum) conditions for ignition of CWS containing petrochemicals by hot particle and establishing the impact of local heat source parameters on the main process characteristic - ignition delay time.

\section{Experimental methods}

Investigation of the conditions and characteristics of ignition of CWS containing petrochemicals by single hot particles carried out using an experimental setup. Its scheme is shown in fig. 1.

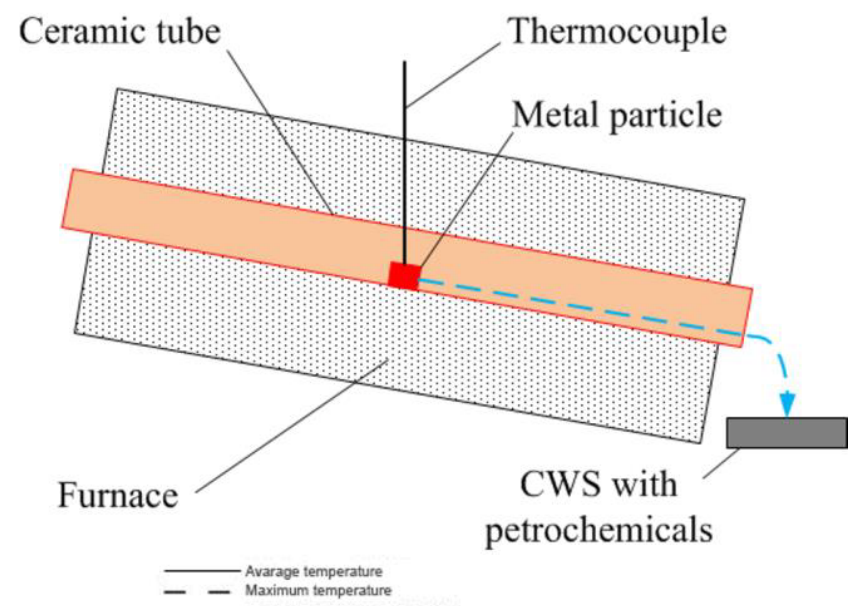

Fig. 1. Scheme of an experimental setup.

The main part of the experimental setup is a ceramic tube with diameter $50 \mathrm{~mm}$ and length $350 \mathrm{~mm}$. The tube is heated to a predetermined temperature before the experiment. After temperature stabilization the metal particle in the disk shape placed in the central part of the ceramic tube. Particle heating takes 5-7 minutes. As a result of short-term mechanical impact hot particle by sliding along the ceramic tube deposited on the surface of CWS containing petrochemicals. The interaction process of local heat source with fuel is fixed by high-speed videocamera Phantom V411 (the frame size 800x600 pixels, the frequency 1000 frames per second).

Steel particles with diameter $10-12 \mathrm{~mm}$ and high $4-8 \mathrm{~mm}$ is used in experiments. Its initial temperature is varied in the range of 950-1100 K. Flame appearance in the vicinity of the particle corresponds to the ignition moment. Ignition is considered stable if the flame was observed more than $3 \mathrm{~s}$ after combustion initiation. About 5-8 approaches carried out under identical conditions to determine the ignition delay time.

CWS containing petrochemicals contains two combustible components: brown coal from the "Borodinskiy" section of the Krasnoyarsk region and used engine oil. Main characteristics of fuel components shown on Table 1 and 2. 
Table 1. The results of technical and elemental analysis of brown coal from the "Borodinskiy" section of the Krasnoyarsk region.

\begin{tabular}{|c|c|c|c|c|c|c|c|c|}
\hline$W^{\mathrm{a}}, \%$ & $A^{\mathrm{d}}, \%$ & $V^{\text {daf }} \%$ & $\begin{array}{c}Q_{\mathrm{s}}^{\mathrm{a}}, \\
\mathrm{MJ} / \mathrm{kg}\end{array}$ & $\mathrm{C}^{\text {daf }} \%$ & $\mathrm{H}^{\text {daf }}, \%$ & $\mathrm{~N}^{\text {daf }} \%$ & $\mathrm{~S}^{\text {daf }}, \%$ & $\mathrm{O}^{\text {daf }}, \%$ \\
\hline 4.11 & 4.12 & 47.63 & 22.91 & 73.25 & 6.516 & 0.79 & 0.435 & 18.99 \\
\hline
\end{tabular}

Table 2. The main characteristics of petrochemical (used engine oil).

\begin{tabular}{|c|c|c|c|c|c|}
\hline $\begin{array}{c}\text { Density at } \\
293 \mathrm{~K}, \mathrm{~kg} / \mathrm{m}^{3}\end{array}$ & $\begin{array}{c}\text { Humidity, } \\
\%\end{array}$ & $\begin{array}{c}\text { Ash, } \\
\%\end{array}$ & $\begin{array}{c}\text { Flash } \\
\text { temperature, } \mathrm{K}\end{array}$ & $\begin{array}{c}\text { Ignition } \\
\text { temperature, } \mathrm{K}\end{array}$ & $\begin{array}{c}\text { Heat of combustion, } \\
\mathrm{MJ} / \mathrm{kg}\end{array}$ \\
\hline 871 & 0.28 & 0.78 & 405 & 491 & 44 \\
\hline
\end{tabular}

The mass fraction of components in CWS containing petrochemicals are coal $45 \%$, water $45 \%$, used engine oil $10 \%$.

\section{Results and discussion}

Fig. 2 shows dependences of ignition delay time of CWS containing petrochemicals on initial temperature of hot steel particle.

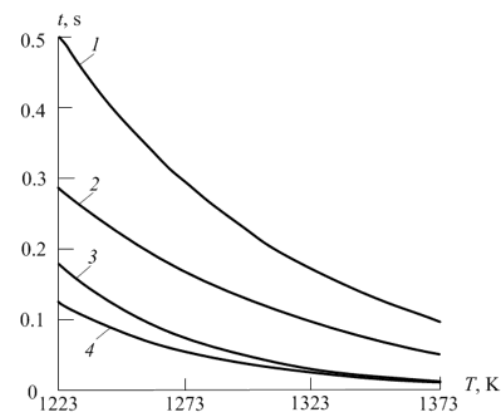

Fig. 2. Dependences of CWS containing petrochemicals ignition delay time on initial temperature of hot particle: $1-d=10 \mathrm{~mm}, h=4 \mathrm{~mm} ; 2-d=10 \mathrm{~mm}, h=6 \mathrm{~mm} ; 3-d=12 \mathrm{~mm}, h=5 \mathrm{~mm} ; 4-d=12 \mathrm{~mm}$, $h=8 \mathrm{~mm}$.

Curves 1-4 (fig. 2) shows the exponential dependence of the ignition delay time of fuel composition on hot particle initial temperature. Obtained result agrees well with the main provisions of the chemical kinetics [13].

The higher initial temperature of steel particle the lower ignition delay time of CWS containing petrochemicals. The minimum duration of the induction period corresponds to particles with a maximum heat content $(d=12 \mathrm{~mm}, h=8 \mathrm{~mm})$. Heat content of particle decreases when its size reducing. It leads to an increasing of ignition delay time (fig. 2).

Video frames of ignition are presented in fig. 3 during interaction process of hot particle with CWS containing petrochemicals.

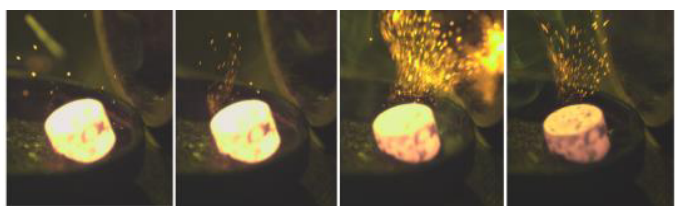

Fig. 3. Video frames of CWS containing petrochemicals ignition by hot particle. 
It is shown (fig. 3) that at the initial moment products of flammable liquid evaporation ignites in the vicinity of the particle. Similar phase transitions occur during heating of liquid droplets on metal substrates $[14,15]$. As a result of fuel near surface layer heating happens enhancement of combustible liquid evaporation. Volatiles stream contains small coal particles that combustion in oxidant medium.

\section{Conclusion}

Ignition of CWS containing petrochemicals by hot steel particle is experimentally investigated. The limit conditions (temperature higher $950 \mathrm{~K}$ ) for fuel composition ignition by local heat source is established. The dependence of the main process characteristics (ignition delay time) on the initial particle temperature is exponential.

\section{Acknowledgments}

This work was supported by the grant of the President of the Russian Federation MK6491.2016.8.

\section{References}

1. S. Tavangar, S.H. Hashemabadi, A. Saberimoghadam, Fuel Process. Technol. 132, 153 (2015)

2. S. Belošević, I. Tomanović, V. Beljanski, D Tucaković, T. Živanović, Appl. Therm. Eng. 74, 102 (2015)

3. G.V. Kuznetsov, V.V. Salomatov, S.V. Syrodoy, Combust., Explos. Shock Waves 51, 4 (2015)

A. Kijo-Kleczkowska, Fuel 90, 2 (2011)

4. E.G. Gorlov, Solid Fuel Chem. 38, 6 (2004)

5. I.I. Lishtvan, P.L. Falyushin, E.A. Smolyachkova, S.I. Kovrik, Solid Fuel Chem. 43, 1 (2009)

6. S.E. Pashchenko, V.V. Salomatov, S.V. Alekseyenko, Method for Hydrocarbon Fuel Combustion. Patent for invention RUS 240794703.08 .2009 (2009) [in Russian]

7. A.Z. Zhuk, B.V. Kleymenov, A.E. Sheindlin, Therm. Eng. 58, 1154 (2011)

8. K.Yu. Vershinina, D.O. Glushkov, P.A. Strizhak, G.V. Kuznetsov, Solid Fuel Chem. 50 (2016)

9. D.O. Glushkov, P.A. Strizhak, K.Yu. Vershinina, Applied Therm. Eng. 96, 536 (2016)

10. D.O. Glushkov, D.P. Shabardin, P.A. Strizhak, K.Yu Vershinina, Fuel Process. Technol. 143, 60 (2016)

11. D.O. Glushkov, S.V. Syrodoy, A.V. Zhakharevich, P.A. Strizhak, Fuel Process. Technol. 148, 224 (2016)

12. D.A. Frank-Kamenetskii, Diffusion and Heat Transfer in Chemical Kinetics (Nauka, Moscow, 1987) [in Russian]

13. G.V. Kuznetsov, D.V. Feoktistov, E.G. Orlova, Thermophysics and Aeromechanics 23, 17 (2016)

14. G.V. Kuznetsov, D.V. Feoktistov, E.G. Orlova, J. Eng. Phys. Thermophys. 89, 317 (2016) 